\title{
Development of Polymer Based Nanocomposites as a Marker of Cadmium in Complex Matrices
}

\author{
Abdullah M. Asiri, ${ }^{1,2}$ Kalsoom Akhtar, ${ }^{3}$ Jongchul Seo, ${ }^{4}$ Hadi M. Marwani, ${ }^{1,2}$ Dowan Kim, ${ }^{4}$ \\ Haksoo Han, ${ }^{5}$ and Sher Bahadar Khan ${ }^{1,2}$ \\ ${ }^{1}$ Center of Excellence for Advanced Materials Research (CEAMR), King Abdulaziz University, P.O. Box 80203, \\ Jeddah 21589, Saudi Arabia \\ ${ }^{2}$ Department of Chemistry, Faculty of Science, King Abdulaziz University, P.O. Box 80203, Jeddah 21589, Saudi Arabia \\ ${ }^{3}$ Division of Nano Sciences and Department of Chemistry, Ewha Womans University, Seoul 120-750, Republic of Korea \\ ${ }^{4}$ Department of Packaging, Yonsei University, Wonju-si, Gangwon-do 720-221, Republic of Korea \\ ${ }^{5}$ Department of Chemical Engineering, Yonsei University, 134 Shinchon-dong, Seodaemun-gu, Seoul 120-749, Republic of Korea
}

Correspondence should be addressed to Sher Bahadar Khan; drkhanmarwat@gmail.com

Received 19 May 2014; Revised 24 November 2014; Accepted 29 November 2014

Academic Editor: Tianxi Liu

Copyright (C) 2015 Abdullah M. Asiri et al. This is an open access article distributed under the Creative Commons Attribution License, which permits unrestricted use, distribution, and reproduction in any medium, provided the original work is properly cited.

Poly(propylene carbonate)/ $\beta$-cyclodextrin (PPC-BCD) nanocomposites were developed as effective extractor for a specific extraction and separation of cadmium(II) by use of inductively coupled plasma-optical emission spectrometry. The selectivity of nanocomposites with different wt\% of BCD (PPC-BCD 0.5, PPC-BCD 1, PPC-BCD 3, PPC-BCD 5, or PPC-BCD 10) was investigated toward $\mathrm{Cd}(\mathrm{II})$. Based on selectivity and $\mathrm{pH}$ studies, $\mathrm{Cd}(\mathrm{II})$ was the most quantitatively adsorbed on PPC-BCD 5 phase at $\mathrm{pH}$ 6, indicating that PPC-BCD 5 was the most selective toward Cd(II) among other nanocomposites. On the basis of adsorption isotherm study, the superior adsorption capacity of PPC-BCD 5 phase for Cd(II) was found to be $149.25 \mathrm{mg} \cdot \mathrm{g}^{-1}$, following the Langmuir adsorption isotherm model. The kinetic of adsorption for Cd(II) has been examined by pseudo-first- and second-order models. The kinetic exploration suggested a pseudo-second-order kinetic model for the adsorption of Cd(II) on the PPC-BCD 5. Additionally, results of thermodynamic investigation demonstrated favorable spontaneous process for the adsorption mechanism of PPC-BCD 5 toward Cd(II).

\section{Introduction}

Petroleum-derived plastics cause the worldwide environment and earth pollution during their production and disposal. Therefore, the development of biodegradable materials such as starch plastics, cellulose plastics, poly(lactic acid), and soy-based plastics has been receiving considerable research attention [1]. Specifically, poly(propylene carbonate) (PPC) which utilizes carbon dioxide has attracted attention due to its good compatibility, resistance, and innocuousness [2]. These specific characteristics are profitable in adhesives, solid electrolytes, barrier materials, plasticizers, and biomedical and packaging applications. But for vast use of PPC, the refining of its thermal, mechanical, and sensing properties is needed by combining with other polymers [3], adding inorganic fillers [4] or chemically modifying the end groups [5].
To improve the mechanical and gas barrier properties of PPC, it was combined with exfoliated graphite (EG) via a solution blending method, resulting in highly enhanced barrier properties [6]. PPC-silica hybrid films showed proficient aqueous ethanol sensing properties [7].

Meanwhile, $\beta$-cyclodextrin (BCD) is a cyclic oligosaccharide containing 7 glucopyranose units, which are linked together by $\alpha$ (1-4) connection creating a torus-shaped ring structure with a hydrophilic exterior and a hydrophobic cavity $[8,9]$. BCD is basically nanosized material with outer diameter of $154 \mathrm{~nm}$ and cavity diameter of $60 \sim 65 \mathrm{~nm}[10,11]$ and the most interesting ability of BCD is to make inclusion complexes with different organic molecules and metal substances into its hydrophobic cavity through host-guest interactions [8]. These fascinating properties make them auspicious for applications in drug carrier systems, nanoreactors, 
bioactive supramolecular assemblies, molecular recognition, metal extractors, and so forth [8-12].

In general, it is very important to find appropriate methods that meet a quality control for determination of metal ions. However, direct detection of metal ions using analytical methods is insufficient due to their low concentrations and the high concentration of interfering matrix components in most real samples. Thus, an effective separation technique is generally necessary for accurate and effective extraction of metal ions. A wide range of treatment techniques are there for separation of metal ions, for example, precipitation [13], liquid-liquid extraction [14], ion exchange [15], cloud point extraction [16], and solid phase extraction (SPE) [17, 18]. Among numerous methods, adsorption technique is doubtless the cost-effective and proficient method and has extensive applications in different fields. Different types of adsorbents comprising inorganic oxides [19-21], zeolites [22], silica [23-25], various resins [26-30], biological adsorbents [31], activated carbon [32, 33], and carbon nanotubes [34] are utilized as adsorption materials.

Similarly, this investigation was devoted to studying and evaluating the effectiveness of newly synthesized PPC-BCD 5 as a specific solid phase extractor for $\mathrm{Cd}(\mathrm{II})$ by inductively coupled plasma-optical emission spectrometry. The selectivity of PPC (PPC-BCD 0.5, PPC-BCD 1, PPC-BCD 3, PPC-BCD 5, or PPC-BCD 10) toward Cd(II) was studied. In addition, the influence of $\mathrm{pH}$ on the selectivity and effectiveness of PPC-BCD 5 for adsorption of Cd(II) was investigated. Other parameters, like concentration and contact time effects, pursuing the supreme uptake of $\mathrm{Cd}(\mathrm{II})$ on the PPCBCD 5 phase were explored under batch techniques. The thermodynamic behavior of Cd(II) adsorption on the PPCBCD 5 phase was also investigated.

\section{Experimental}

2.1. Chemicals and Reagents. Poly(propylene carbonate) (PPC) was delivered by SK Innovation Co., Ltd. (Cheonan, Korea). $\beta$-cyclodextrin (BCD, purity $>97 \%$ ) was purchased from Sigma-Aldrich (Yongin, Korea). Dimethylformamide (DMF) was bought from Duksan Chemical Co., Ltd. (Ansan, Korea). All other chemicals were bought from Sigma-Aldrich (Milwaukee, WI, USA). In the experiment, double distilled deionized water was used.

2.2. Preparation of the New Solid Phase Extractor. In this study, five different PPC-BCD extractors were prepared via solution method. Firstly, $30 \mathrm{~mL}$ of PPC (2 g) solution was prepared by dissolving in $\mathrm{DMF}$ at $50^{\circ} \mathrm{C}$. A dispersed solution of BCD was prepared in DMF using 20 min ultrasonication. To explore the influence of BCD on the extraction properties, formulations with several different BCD contents were prepared: $0.5,1,3,5$, and $10 \mathrm{wt} \%$ with respect to the PPC content. These samples depending on the PPC content were coded as PPC-BCD 0.5, PPC-BCD 1, PPC-BCD 3, PPC-BCD 5, and PPC-BCD 10, respectively. The PPC-BCD solutions were gently put onto a glass plate and kept for $2 \mathrm{hr}$ drying at $120^{\circ} \mathrm{C}$. The dried extractor films were approximately $35 \mu \mathrm{m}$ thick by using a digital micrometer (Mitutoyo Co., Japan).

2.3. Adsorption Method Procedure. A standard solution of $\mathrm{Cd}(\mathrm{II})$ was made in $18.2 \mathrm{M} \Omega \cdot \mathrm{cm}$ distilled water and kept at $4^{\circ} \mathrm{C}$. The standard solutions of $1 \mathrm{mg} \mathrm{L}^{-1}$ of $\mathrm{Cd}(\mathrm{II})$ were made for selectivity and individually mixed with $20 \mathrm{mg}$ PPC (PPC-BCD 0.5, PPC-BCD 1, PPC-BCD 3, PPC-BCD 5, or PPC-BCD 10). In addition, standard solutions of $1 \mathrm{mg} \mathrm{L}^{-1}$ $\mathrm{Cd}(\mathrm{II})$ ion were made in the $\mathrm{pH}$ values ranging from 1.0 to 9.0 with appropriate buffer solutions, $0.2 \mathrm{~mol} \mathrm{~L}^{-1} \mathrm{HCl} / \mathrm{KCl}$ for $\mathrm{pH} 1.0$ and $2.0,0.1 \mathrm{~mol} \mathrm{~L}^{-1} \mathrm{CH}_{3} \mathrm{COOH} / \mathrm{CH}_{3} \mathrm{COONa}$ for $\mathrm{pH}$ 3.0-6.0, and $0.1 \mathrm{~mol} \mathrm{~L}^{-1} \mathrm{Na}_{2} \mathrm{HPO}_{4} / \mathrm{HCl}$ for $\mathrm{pH} 7.0-9.0$. Then, all standard solutions were individually mixed with $20 \mathrm{mg}$ PPC-BCD 5 in order to study the effect of $\mathrm{pH}$ on the selectivity of PPC-BCD 5 adsorption toward Cd(II). All mixtures were shaken for $1 \mathrm{~h}$ using a mechanical shaker at $150 \mathrm{rpm}$ and room temperature. The PPC-BCD 5 phase was then removed by filtration, and the concentration of metal ion of interest in the aqueous solution was checked by inductively coupled plasma-optical emission spectrometer. For investigation of adsorption capacity of $\mathrm{Cd}$ (II) under batch conditions, standard solutions of 5, 10, 15, 20, 30, 50, $75,100,125,150,200$, and 250 were made as above, set to the ideal $\mathrm{pH}$ value of 6.0 , and separately mixed with $20 \mathrm{mg}$ PPC-BCD 5. Additionally, the influence of contact time on $\mathrm{Cd}$ (II) uptake capacity was performed at similar batch conditions but at dissimilar equilibrium periods $(2.5,5,10$, $20,30,40,50$, and $60 \mathrm{~min})$. For thermodynamic investigation, standard solutions of $5 \mathrm{mg} \mathrm{L}^{-1} \mathrm{Cd}$ (II) were made, set to the $\mathrm{pH}$ value of 6.0 , and separately mixed with $20 \mathrm{mg}$ PPCBCD 5. Thermodynamic study of the adsorption of PPCBCD 5 toward Cd(II) was also performed at similar batch circumstances at diverse temperatures $(273,298,313,338$, and $353 \mathrm{~K})$.

2.4. Instrumentation. The buffer's $\mathrm{pH}$ was measured by a $\mathrm{pH}$ meter (InoLab pH 7200, IL, USA). Inductively coupled plasma-optical emission spectrometer (ICP-OES) model Optima 4100 DV, USA, was utilized for the determination of $\mathrm{Cd}(\mathrm{II})$. The ICP-OES instrument was optimized every day before measurement and used with the following parameters: FR power, $1300 \mathrm{~kW}$; frequency, $27.12 \mathrm{MHz}$; demountable quartz torch, Ar/Ar/Ar; plasma gas (Ar) flow, 15.0 $\mathrm{L} \mathrm{min}^{-1}$; auxiliary gas (Ar) flow, $0.2 \mathrm{~L} \mathrm{~min}^{-1}$; nebulizer gas (Ar) flow, $0.8 \mathrm{~L} \mathrm{~min}^{-1}$; nebulizer pressure, 2.4 bar; glass spray chamber according to Scott (Ryton), sample pump flow rate, $1.5 \mathrm{~mL} \mathrm{~min}^{-1}$; integration time, $3 \mathrm{~s}$; replicates, 3 ; and wavelength range of monochromator, $165-460 \mathrm{~nm}$. Concentrations of $\mathrm{Cd}$ (II) were determined at wavelengths of $228.80 \mathrm{~nm}$ for Cd(II).

\section{Results and Discussion}

3.1. Selectivity Study. Selectivity of PPC (PPC-BCD 0.5, PPCBCD 1, PPC-BCD 3, PPC-BCD 5, or PPC-BCD 10) toward $\mathrm{Cd}(\mathrm{II})$ was studied based on calculation of the distribution 
TABLE 1: Selectivity study of different phases $(20 \mathrm{mg})$ of adsorption toward $\mathrm{Cd}(\mathrm{II})(N=3)$.

\begin{tabular}{lcc}
\hline Phase & $q_{e}\left(\mathrm{mg} \mathrm{g}^{-1}\right)$ & $K_{d}\left(\mathrm{~mL} \mathrm{~g}^{-1}\right)$ \\
\hline PPC & 1.213 & $4.04 \times 10^{4}$ \\
PPC-BCD 0.5 & 1.205 & $3.35 \times 10^{4}$ \\
PPC-BCD 1 & 1.180 & $2.11 \times 10^{4}$ \\
PPC-BCD 3 & 1.158 & $1.56 \times 10^{4}$ \\
PPC-BCD 5 & 1.248 & $7.80 \times 10^{5}$ \\
PPC-BCD 10 & 1.178 & $2.03 \times 10^{4}$ \\
\hline
\end{tabular}

coefficient. The distribution coefficient $\left(K_{d}\right)$ can be acquired from the following equation [35]:

$$
K_{d}=\frac{\left(C_{o}-C_{e}\right)}{C_{e}} \times \frac{V}{m}
$$

where $C_{o}$ and $C_{e}$ are the initial and final concentrations before and after filtration with the adsorbent, respectively, $V$ refers to the volume $(\mathrm{mL})$, and $m$ is the weight of adsorbent $(\mathrm{g})$. Distribution coefficient values examined in current study are illustrated in Table 1. As revealed in Table 1, PPC-BCD 5 phase has the maximum distribution coefficient value $\left(7.80 \times 10^{5} \mathrm{~mL} \mathrm{~g}^{-1}\right)$ toward $\mathrm{Cd}(\mathrm{II})$ among all other phases. The present study results specified that the selectivity of newly prepared PPC-BCD 5 phase toward Cd(II) was highest as compared to other phases investigated in this study.

3.2. Effect of $p H$. Extraction of metal ions from aqueous media by process of adsorption is usually $\mathrm{pH}$ dependent because $\mathrm{pH}$ has an effect on the surface charge of adsorbent, the extent of ionization, and species of adsorbate [34]. In the current study, the influence of $\mathrm{pH}$ on the adsorption of $\mathrm{Cd}$ (II) by newly synthesized PPC-BCD 5 phase was investigated. A concentration of $1 \mathrm{mg} \mathrm{L}^{-1} \mathrm{Cd}(\mathrm{II})$ was chosen, and $\mathrm{pH}$ values were adjusted to a range from 1.0 to 9.0 with corresponding buffer solutions. All standard solutions were individually mixed with $20 \mathrm{mg}$ PPC-BCD 5. The percentage extraction of $\mathrm{Cd}(\mathrm{II})$ was calculated based on a difference between the initial $\left(C_{o}\right)$ and final $\left(C_{e}\right)$ concentrations before and after filtration with PPC-BCD 5, respectively, as follows:

$$
\% \text { Extraction }=\frac{C_{o}-C_{e}}{C_{o}} \times 100 .
$$

It can be clearly observed from Figure 1 that the \% extraction is strongly reliant on the $\mathrm{pH}$ value of solution. Figure 1 depicts that there is an upsurge followed by a succeeding decline in the $\%$ extraction of $\mathrm{Cd}(\mathrm{II})$ with a rise of the $\mathrm{pH}$ value from 1.0 up to 9.0. This behavior is consistent with the saturation of binding sites of PPC-BCD 5 with $\mathrm{Cd}(\mathrm{II})$. However, it is motivating to notice that the \% extraction of Cd(II) reached the highest percentage (99.80\%) at $\mathrm{pH}$ 6.0, providing that the PPC-BCD 5 phase was most selective toward $\mathrm{Cd}(\mathrm{II})$ at this $\mathrm{pH}$ value.

The highest percentage of Cd(II) extraction and selectivity at $\mathrm{pH} 6.0$ with PPC-BCD 5 phase can be possibly due to the electrostatic interaction between positively charged

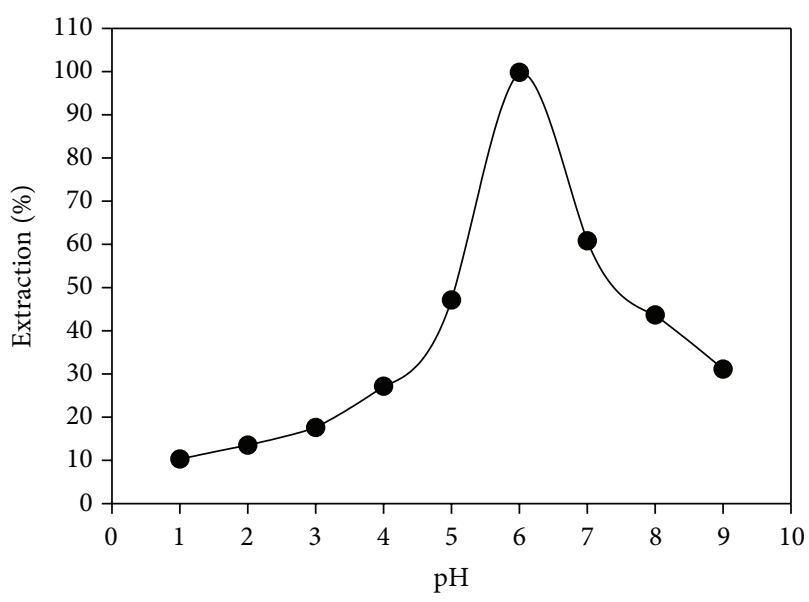

FIGURE 1: Effect of $\mathrm{pH}$ on the adsorption of $1 \mathrm{mg} \mathrm{L}^{-1} \mathrm{Cd}(\mathrm{II})$ on $20 \mathrm{mg}$ PPC-BCD 5 phase at $25^{\circ} \mathrm{C}$.

Cd(II) ions and negatively charged sites presented on PPC$\mathrm{BCD}$ 5. Seeing the above results, the optimum $\mathrm{pH}$ value of 6.0 was chosen to be the optimum regarding examination of other parameters responsible for its maximum uptake on PPC-BCD 5 under static conditions.

3.3. Determination of Adsorption Capacity. Adsorption capacity represents the utmost metal amount taken up by $1 \mathrm{~g}$ of solid phase and presented by mg metal $\mathrm{g}^{-1}$. In this study, the uptake capacity of $\mathrm{Cd}(\mathrm{II})$ was investigated by varying amounts of Cd(II) and individually mixing them with $20 \mathrm{mg}$ PPC-BCD 5 at pH 6.0 under batch procedure. Adsorption capacity can be expressed using the following:

$$
q_{e}=\frac{\left(C_{o}-C_{e}\right) V}{m}
$$

where $q_{e}$ denotes the adsorbed $\mathrm{Cd}(\mathrm{II})$ by PPC-BCD 5 $\left(\mathrm{mg} \mathrm{g}^{-1}\right), C_{o}$ and $C_{e}$ refer to the initial and equilibrium concentrations of Cd(II) ion in solution $\left(\mathrm{mg} \mathrm{L}^{-1}\right)$, respectively, $V$ is the volume (L), and $m$ is the weight of PPC-BCD $5(\mathrm{~g})$. From adsorption isotherm study, the adsorption capability of PPC-BCD 5 for Cd(II) was determined to be $149.25 \mathrm{mg} \mathrm{g}^{-1}$ (Figure 2), which is more in quantity as compared to those formerly reporting the adsorption capacity of $\mathrm{Cd}(\mathrm{II})$ with other adsorbents (4.92 [36], 9.39 [37], 84.30 [38], 57.90 [39], 97.36 [40], and 123.65 [41] $\mathrm{mg} \mathrm{g}^{-1}$ ).

3.4. Adsorption Isotherm Models. It is very important to study adsorption isotherm models for the development of equation that precisely symbolizes the results. Both Langmuir and Freundlich adsorption isotherm models $[42,43]$ were utilized to deduce equilibrium isotherm data. In this study, experimental data were well correlated to Langmuir equation. The Langmuir isotherm model represents the monolayer adsorption onto a surface containing a finite number of adsorption sites of uniform energies of adsorption with no transmigration of adsorbate in the plane of the surface. 


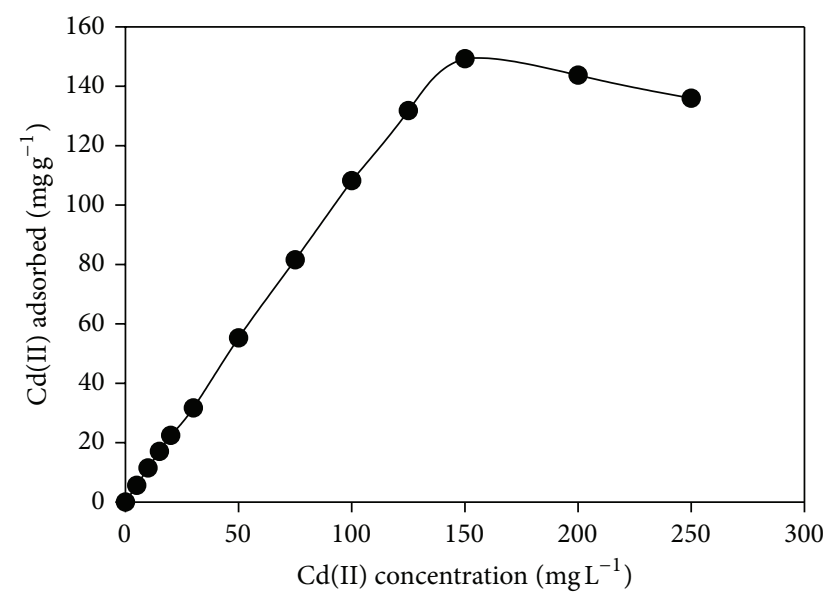

Figure 2: Adsorption profile of Cd(II) on $20 \mathrm{mg}$ PPC-BCD 5 in relation to the concentration at $\mathrm{pH} 6.0$ and $25^{\circ} \mathrm{C}$.

The Langmuir classical adsorption isotherm can be stated as follows [44]:

$$
\frac{C_{e}}{q_{e}}=\left(\frac{C_{e}}{Q_{o}}\right)+\frac{1}{Q_{o} b},
$$

where $C_{e}$ is the concentration of metal ion in solution at equilibrium $\left(\mathrm{mg} \mathrm{mL}^{-1}\right)$ and $q_{e}$ refers to the amount of metal ion per gram of the adsorbent at equilibrium $\left(\mathrm{mg} \mathrm{g}^{-1}\right)$. The symbols $Q_{o}$ and $b$ refer to Langmuir constants for PPCBCD 5 and are related to the maximum $\mathrm{Cd}(\mathrm{II})$ adsorption capacity $\left(\mathrm{mg} \mathrm{g}^{-1}\right)$ and affinity parameter $\left(\mathrm{L} \mathrm{mg}^{-1}\right)$ in that order. Langmuir constants $Q_{o}$ and $b$ can be calculated from a linear plot of $C_{e} / q_{e}$ against $C_{e}$ with a slope and intercept equal to $1 / Q_{o}$ and $1 / Q_{o} b$, respectively. Moreover, vital features of the Langmuir adsorption isotherm model can be obtained in terms of a dimensionless constant separation factor or equilibrium parameter, $R_{L}$, which is represented as follows:

$$
R_{L}=\frac{1}{\left(1+b C_{o}\right)},
$$

where $b$ is the Langmuir constant, demonstrating the nature of adsorption and shape of isotherm and $C_{o}$ denotes the initial concentration of $\mathrm{Cd}(\mathrm{II})$. The value of $R_{L}$ describes the nature of the adsorption isotherm, and $R_{L}$ values between 0 and 1 represent a favorable adsorption [45].

A linear plot was obtained from Langmuir isotherm equation based on the least square fit, verifying the validity of Langmuir adsorption isotherm model (Figure 3). Based on the above results, one can conclude that the adsorption method was chiefly monolayer on a homogeneous PPCBCD 5 surface. Calculated Langmuir constants $Q_{o}$ and $b$ are determined to be $150.44 \mathrm{mg} \mathrm{g}^{-1}$ and $0.11 \mathrm{~L} \mathrm{mg}^{-1}$, respectively. The correlation coefficient $\left(R^{2}\right)$ acquired from the Langmuir model is measured to be 0.986 for adsorption of $\mathrm{Cd}$ (II) on PPC-BCD 5, further showing that the data were well in accordance considering the Langmuir model. The $R_{L}$ value of Cd(II) adsorption on PPC-BCD 5 is 0.06 , making an extremely favorable adsorption route based on

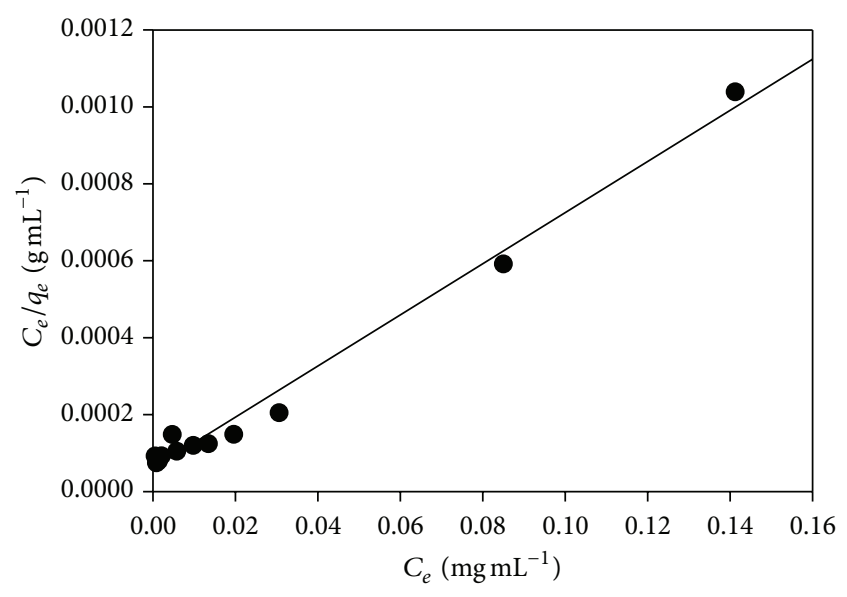

FIGURE 3: Langmuir adsorption isotherm model of Cd(II) adsorption on $20 \mathrm{mg}$ PPC-BCD 5 at $\mathrm{pH} 6.0$ and $25^{\circ} \mathrm{C}$. Adsorption experiments were obtained at different concentrations $\left(5-250 \mathrm{mg} \mathrm{L}^{-1}\right)$ of $\mathrm{Cd}(\mathrm{II})$ under batch conditions.

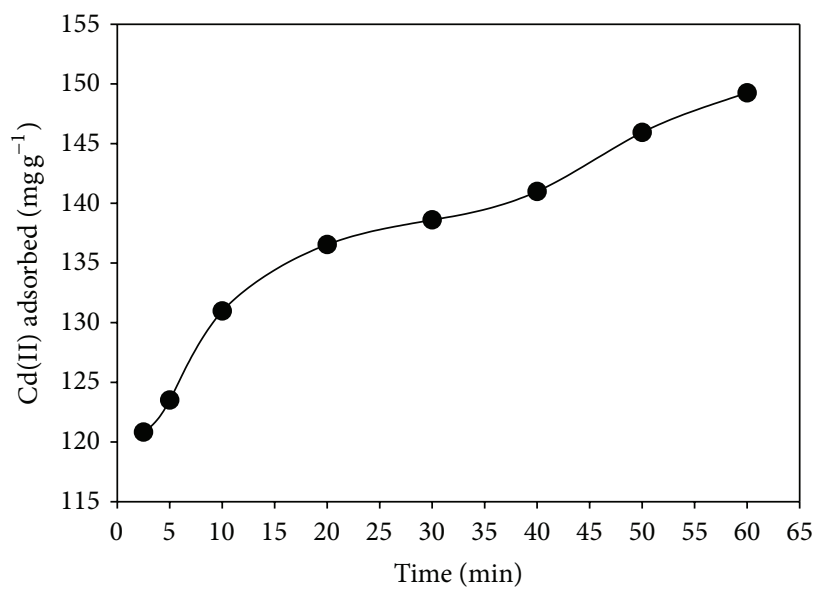

FIGURE 4: Effect of contact time on the adsorption of $150 \mathrm{mg} \mathrm{L}^{-1}$ $\mathrm{Cd}(\mathrm{II})$ on $20 \mathrm{mg}$ PPC-BCD 5 at $\mathrm{pH} 6.0$ and $25^{\circ} \mathrm{C}$.

the Langmuir model possible. One can also observe that the Cd(II) adsorption capacity $\left(150.44 \mathrm{mg} \mathrm{g}^{-1}\right.$ ) evaluated from Langmuir equation was strongly in concurrence with that $\left(149.25 \mathrm{mg} \mathrm{g}^{-1}\right)$ experimentally measured from the adsorption isotherm study.

3.5. Effect of Contact Time. The effect of shaking time on the $\%$ extraction of $\mathrm{Cd}$ (II) is a significant factor for calculating the possible prejudice order regarding the behavior of PPC-BCD 5 adsorption toward $\mathrm{Cd}(\mathrm{II})$ and finding the approximate time needed to acquire equilibrium. In this study, various contact times varying from 2.5 to $60.0 \mathrm{~min}$ were examined at the concentration of $150 \mathrm{mg} \mathrm{L}^{-1} \mathrm{Cd}(\mathrm{II})$ (Figure 4). As displayed in Figure 4, the amount of Cd(II) adsorbed onto PPC-BCD 5 phase significantly increased with increasing contact time, indicating that PPC-BCD 5 had rapid adsorption kinetics for $\mathrm{Cd}(\mathrm{II})$. It can be clearly observed from Figure 4 that over $130 \mathrm{mg} \mathrm{g}^{-1} \mathrm{Cd}(\mathrm{II})$ was adsorbed on the PPC-BCD 5 phase 
TABLE 2: Calculated thermodynamic parameters of $5 \mathrm{mg} \mathrm{L}^{-1} \mathrm{Cd}(\mathrm{II})$ adsorption on $20 \mathrm{mg}$ PPC-BCD $0.5(N=3)$.

\begin{tabular}{|c|c|c|c|c|c|c|}
\hline \multirow{2}{*}{$\Delta H^{\circ}\left(\mathrm{kJ} \mathrm{mol}{ }^{-1}\right)$} & \multirow{2}{*}{$\Delta S^{\circ}\left(\mathrm{J} \mathrm{mol}^{-1} \mathrm{~K}^{-1}\right)$} & \multicolumn{5}{|c|}{$\Delta G^{\circ}\left(\mathrm{kJ} \mathrm{mol}^{-1}\right)$} \\
\hline & & $T=273 \mathrm{~K}$ & $T=298 \mathrm{~K}$ & $T=313 \mathrm{~K}$ & $T=338 \mathrm{~K}$ & $T=353 \mathrm{~K}$ \\
\hline-9.34 & 46.18 & -22.05 & -23.01 & -23.64 & -25.09 & -25.66 \\
\hline
\end{tabular}

after only $10 \mathrm{~min}$ of the equilibrium periods. The amount of $\mathrm{Cd}(\mathrm{II})$ adsorbed was also increased up to more than $138 \mathrm{mg} \mathrm{g}^{-1}$ after $30 \mathrm{~min}$ until the maximum adsorption of PPC-BCD 5 for Cd(II) reached $149.25 \mathrm{mg} \mathrm{g}^{-1}$ after $60 \mathrm{~min}$.

3.6. Kinetic Study. The effect of concentration on reaction rates is very essential in understanding the reaction mechanism. The adsorption kinetic data of Cd(II) adsorption on PPC-BCD 5 were investigated in terms of pseudo-first- and second-order kinetic equations [46] for the measurement of changes in adsorption regarding time and calculating kinetic parameters. Kinetic models were utilized for fitting of experimental data having the correlation coefficient $\left(R^{2}\right)$ as assess of agreement between the experimental data. The pseudo-first-order equation can be expressed as follows:

$$
\log \left(q_{e}-q_{t}\right)=\log q_{e}-\left(\frac{k_{1}}{2.303}\right) t
$$

where $k_{1}\left(\mathrm{~min}^{-1}\right)$ refers to the rate constant of the pseudofirst-order adsorption, $q_{t}\left(\mathrm{mgg}^{-1}\right)$ represents the amount of adsorption at time $t(\mathrm{~min})$, and $q_{e}\left(\mathrm{mgg}^{-1}\right)$ denotes the amount of adsorption at equilibrium. The adsorption rate constant $\left(k_{1}\right)$ and adsorption capacity $\left(q_{e}\right)$ for PPC-BCD 5 were calculated from the slope and intercept, respectively, of the plot of $\log \left(q_{e}-q_{t}\right)$ against $t$.

The adsorption kinetic data of $\mathrm{Cd}(\mathrm{II})$ adsorbed on PPCBCD 5 were also studied in terms of a pseudo-second-order adsorption. The pseudo-second-order model explains that the rate limiting step is possibly chemical adsorption relating valence forces through sharing or exchanging of electrons between the adsorbent and adsorbate [47]. The pseudosecond-order equation can be written as follows:

$$
\frac{t}{q_{t}}=\frac{1}{v_{o}}+\left(\frac{1}{q_{e}}\right) t
$$

where $v_{o}=k_{2} q_{e}^{2}$ denotes the initial adsorption rate $(\mathrm{mg}$ $\left.\mathrm{g}^{-1} \mathrm{~min}^{-1}\right), k_{2}\left(\mathrm{~g} \mathrm{mg}^{-1} \mathrm{~min}^{-1}\right)$ corresponds to the rate constant of adsorption, $q_{e}\left(\mathrm{mgg}^{-1}\right)$ refers to the amount of metal ion adsorbed at equilibrium, and $q_{t}\left(\mathrm{mgg}^{-1}\right)$ is the amount of metal ion on the surface of adsorbent at any time $t$ (min). The parameters $q_{e}$ and $v_{o}$ can be easily attained from the slope and intercept, respectively, of a plot of $t / q_{t}$ versus $t$ (Figure 5). It is interesting to note that adsorption kinetics data fitted well with the second-order kinetic model. The correlation coefficient $\left(R^{2}\right)$ factor was measured to be 0.99 , showing the reliability and accuracy of the pseudosecond-order adsorption. The parameters $q_{e}, v_{o}$, and $k_{2}$ were determined to be $149.84 \mathrm{mg} \mathrm{g}^{-1}, 103.64 \mathrm{mg} \mathrm{g}^{-1} \mathrm{~min}^{-1}$, and $0.005 \mathrm{~g} \mathrm{mg}^{-1} \mathrm{~min}^{-1}$. The adsorption capacity of $\mathrm{Cd}(\mathrm{II})$

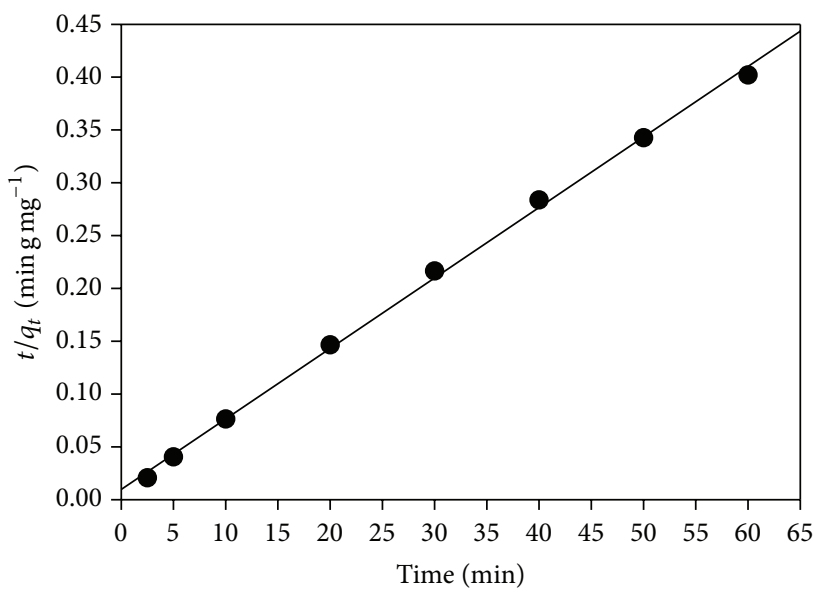

FIgURE 5: Pseudo-second-order adsorption kinetic model of Cd(II) uptake on $20 \mathrm{mg}$ PPC-BCD 5 at $\mathrm{pH} 6.0$ and $25^{\circ} \mathrm{C}$.

on PPC-BCD 5 estimated from the pseudo-second-order kinetic model $\left(149.84 \mathrm{mg} \mathrm{g}^{-1}\right)$ was also in good agreement with adsorption capacities obtained from both adsorption isotherm experiments $\left(149.25 \mathrm{mg} \mathrm{g}^{-1}\right)$ and Langmuir isotherm model ( $\left.150.44 \mathrm{mg} \mathrm{g}^{-1}\right)$, confirming the fact that the pseudo-second-order nature of the adsorption of $\mathrm{Cd}(\mathrm{II})$ on PPC-BCD 5 is highly applicable.

3.7. Thermodynamic Study. The study of thermodynamic parameters offers a good understanding of mechanism for the adsorption of $\mathrm{Cd}(\mathrm{II})$ on PPC-BCD 5. Therefore, the influence of temperature regarding the adsorption of $20 \mathrm{mg}$ PPC-BCD 5 for $5 \mathrm{mg} \mathrm{L}^{-1} \mathrm{Cd}(\mathrm{II})$ was investigated at varied temperatures $(273,298,313,338$, and $353 \mathrm{~K})$. The distribution adsorption coefficient $\left(K_{d}\right)$ representing the nature of a metal ion adsorbed by an adsorbent $\left(\mathrm{mL} \mathrm{g}^{-1}\right)$ can be acquired from (1). Besides, thermodynamic parameters of the standard enthalpy change $\left(\Delta H^{\circ}, \mathrm{kJ} \mathrm{mol}^{-1}\right)$ and standard entropy change $\left(\Delta S^{\circ}, \mathrm{J} \mathrm{mol}^{-1} \mathrm{~K}^{-1}\right)$ were determined, as summarized in Table 2, from the slope and intercept, respectively, of the linear variation of $\ln K_{d}$ with the reciprocal of temperature $(1 / T)$ as follows:

$$
\ln K_{d}=\frac{\Delta S^{\circ}}{R}-\left(\frac{\Delta H^{\circ}}{R T}\right),
$$

where $R$ denotes the universal gas constant $\left(8.314 \mathrm{~J} \mathrm{~mol}^{-1} \mathrm{~K}^{-1}\right)$ and $T$ represents the temperature in Kelvin. The standard Gibbs free energy change $\left(\Delta G^{\circ}, \mathrm{kJ} \mathrm{mol}^{-1}\right)$ summarized in Table 2 was determined from the following equation:

$$
\Delta G^{\circ}=\Delta H^{\circ}-T \Delta S^{\circ} .
$$


As shown in Table 2, measured values of standard enthalpy change $\Delta H^{\circ}$ and Gibbs free energy change $\Delta G^{\circ}$ are negative, as the standard entropy change $\Delta S^{\circ}$ is positive. The examined negative $\Delta H^{\circ}$ value proposed an exothermic adsorption of Cd(II) on PPC-BCD 5. Additionally, the adsorption mechanism of PPC-BCD 5 toward Cd(II) is believed to be a common spontaneous method and thermodynamically favorable because of the negative $\Delta G^{\circ}$ along with positive $\Delta S^{\circ}$. The positive $\Delta S^{\circ}$ value provides some structural changes in PPCBCD 5 and $\mathrm{Cd}(\mathrm{II})$ and indicates the increased haphazardness during the adsorption process of $\mathrm{Cd}(\mathrm{II})$ on PPC-BCD 5. These results are in accordance with the data measured from adsorption isotherm experiments and Langmuir and kinetic adsorption isotherm models.

\section{Conclusion}

To investigate the feasibility of PPC to apply for the selective detection of toxic metal ion in complex matrices, a series of PPC-BCD extractors were newly prepared by solution blending of biodegradable PPC and BCD. The proposed method based on the newly synthesized PPC-BCD 5 phase not only had the efficiency toward a selective adsorption of $\mathrm{Cd}$ (II) but also provided high uptake capacity of Cd(II). Results obtained from adsorption isotherm models displayed that Langmuir adsorption isotherm model has best described the Cd(II) adsorption on PPC-BCD 5. Kinetic isotherm results demonstrated that the adsorption of PPCBCD 5 toward Cd(II) followed a pseudo-second-order kinetic reaction. Thermodynamic study reveals that the adsorption mechanism of Cd(II) adsorption on PPC-BCD 5 was a common spontaneous method and thermodynamically favorable. Additionally, the adsorption procedure is found to be exothermic in nature. This method can be an useful approach in providing a selective separation and calculation of $\mathrm{Cd}(\mathrm{II})$ from the complex matrices.

\section{Conflict of Interests}

The authors declare that there is no conflict of interests regarding the publication of this paper.

\section{Acknowledgments}

This work was funded by the Deanship of Scientific Research (DSR), King Abdulaziz University, under Grant no. D-004/ 431. The authors, therefore, acknowledge technical and financial support of KAU.

\section{References}

[1] S. J. Wang, L. C. Du, X. S. Zhao, Y. Z. Meng, and S. C. Tjong, "Synthesis and characterization of alternating copolymer from carbon dioxide and propylene oxide," Journal of Applied Polymer Science, vol. 85, no. 11, pp. 2327-2334, 2002.

[2] S. Inoue and T. Tsuruta, "Synthesis and thermal degradation of carbon dioxide-epoxide copolymer," Applied Polymer Science, vol. 26, pp. 257-267, 1975.
[3] X. Ma, P. R. Chang, J. Yu, and N. Wang, "Preparation and properties of biodegradable poly(propylene carbonate)/thermoplastic dried starch composites," Carbohydrate Polymers, vol. 71, no. 2, pp. 229-234, 2008.

[4] X. Shi and Z. Gan, "Preparation and characterization of poly(propylene carbonate)/montmorillonite nanocomposites by solution intercalation," European Polymer Journal, vol. 43, no. 12, pp. 4852-4858, 2007.

[5] S. Peng, Y. An, C. Chen, B. Fei, Y. Zhuang, and L. Dong, "Thermal degradation kinetics of uncapped and end-capped poly(propylene carbonate)," Polymer Degradation and Stability, vol. 80, no. 1, pp. 141-147, 2003.

[6] Y. Lee, D. Kim, J. Seo, H. Han, and S. B. Khan, "Preparation and characterization of poly(propylene carbonate)/exfoliated graphite nanocomposite films with improved thermal stability, mechanical properties and barrier properties," Polymer International, vol. 62, no. 9, pp. 1386-1394, 2013.

[7] S. B. Khan, M. M. Rahman, K. Akhtar et al., "Thermally and mechanically stable eco-friendly nanocomposite for chemical sensor applications," International Journal of Electrochemical Science, vol. 7, pp. 4030-4038, 2012.

[8] A. Z. M. Badruddoza, Z. B. Z. Shawon, T. W. J. Daniel, K. Hidajat, and M. S. Uddin, "Endocrine disrupters and toxic metal ions removal by carboxymethyl- $\beta$-cyclodextrin polymer grafted onto magnetic nanoadsorbents," Journal of Chemical Engineering, vol. 27, no. 1, pp. 69-73, 2013.

[9] M. Ulzii, Y. Kondo, M. Yamada, and F. Hamada, "Metal extraction capability for hybrid polymers consisted of $\beta$-cyclodextrin and diatomite," International Journal of the Society of Materials Engineering for Resources, vol. 19, no. 1-2, pp. 32-36, 2013.

[10] Z.-P. Dou, H. Xing, and J.-X. Xiao, "Hydrogenated and fluorinated host-guest surfactants: complexes of cyclodextrins with alkanes and fluoroalkyl-grafted alkanes," Chemistry-A European Journal, vol. 17, no. 19, pp. 5373-5380, 2011.

[11] E. M. M. del Valle, "Cyclodextrins and their uses: a review," Process Biochemistry, vol. 39, no. 9, pp. 1033-1046, 2004.

[12] K. Uekama, F. Hirayama, and T. Irie, "Cyclodextrin drug carrier systems," Chemical Reviews, vol. 98, no. 5, pp. 2045-2076, 1998.

[13] A. L. Souza, S. G. Lemos, and P. V. Oliveira, "A method for Ca, $\mathrm{Fe}, \mathrm{Ga}, \mathrm{Na}, \mathrm{Si}$ and $\mathrm{Zn}$ determination in alumina by inductively coupled plasma optical emission spectrometry after aluminum precipitation," Spectrochimica Acta-Part B. Atomic Spectroscopy, vol. 66, no. 5, pp. 383-388, 2011.

[14] A. Nasu, S. Yamauchi, and T. Sekine, "Solvent extraction of copper(I) and (II) as thiocyanate complexes with tetrabutylammonium ions into chloroform and with trioctylphosphine oxide into hexane," Analytical Sciences, vol. 13, no. 6, pp. 903-911, 1997.

[15] J. W. Hershey and P. N. Keliher, "Some atomic absorption hydride generation inter-element interference reduction studies utilizing ion exchange resins," Spectrochimica Acta Part B: Atomic Spectroscopy, vol. 44, no. 3, pp. 329-337, 1989.

[16] J. L. Manzoori, H. Abdolmohammad-Zadeh, and M. Amjadi, "Simplified cloud point extraction for the preconcentration of ultra-trace amounts of gold prior to determination by electrothermal atomic absorption spectrometry," Microchimica Acta, vol. 159, no. 1-2, pp. 71-78, 2007.

[17] S. A. Ahmed, "Alumina physically loaded by thiosemicarbazide for selective preconcentration of mercury(II) ion from natural water samples," Journal of Hazardous Materials, vol. 156, no. 1-3, pp. 521-529, 2008.

[18] A. M. Alvarez, J. R. E. Alvarez, and R. P. Alvarez, "Heavy metal analysis of rainwaters: a comparison of TXRF and ASV 
analytical capabilities," Journal of Radioanalytical and Nuclear Chemistry, vol. 273, no. 2, pp. 427-433, 2007.

[19] M. A. Rauf, M. T. Hussain, and S. M. Hasany, "Adsorption of europium on manganese dioxide from binary mixtures of aqueous sulfuric acid and methanol," Separation Science and Technology, vol. 28, no. 13-14, pp. 2237-2245, 1993.

[20] Y.-P. Hang, Y.-C. Qin, Z.-C. Jiang, and B. Hu, "Direct analysis of trace rare earth elements through nanometer-size titanium dioxide separation/concentration and fluorination assisted ETV-ICP-AES with slurry sampling," Chemical Journal of Chinese Universities, vol. 24, no. 11, pp. 1980-1983, 2003.

[21] P. Liang, J. Cao, R. Liu, and Y. Liu, "Determination of trace rare earth elements by inductively coupled plasma optical emission spectrometry after preconcentration with immobilized nanometer titanium dioxide," Microchimica Acta, vol. 159, no. 1-2, pp. 35-40, 2007.

[22] T. Pasinli, A. E. Eroğlu, and T. Shahwan, "Preconcentration and atomic spectrometric determination of rare earth elements (REEs) in natural water samples by inductively coupled plasma atomic emission spectrometry," Analytica Chimica Acta, vol. 547, no. 1, pp. 42-49, 2005.

[23] M. H. Mashhadizadeh, M. Pesteh, M. Talakesh, I. Sheikhshoaie, M. M. Ardakani, and M. A. Karimi, "Solid phase extraction of copper (II) by sorption on octadecyl silica membrane disk modified with a new Schiff base and determination with atomic absorption spectrometry," Spectrochimica Acta-Part B. Atomic Spectroscopy, vol. 63, no. 8, pp. 885-888, 2008.

[24] A. Zhang, Y. Wei, and M. Kumagai, "Separation of minor actinides and rare earths from a simulated high activity liquid waste by two macroporous silica-based polymeric composites," Separation Science and Technology, vol. 42, no. 10, pp. 22352253, 2007.

[25] P. Liang and W. Fa, "Determination of La, Eu and $\mathrm{Yb}$ in water samples by inductively coupled plasma atomic emission spectrometry after solid phase extraction of their 1-phenyl3-methyl-4-benzoylpyrazol-5-one complexes on silica gel column," Microchimica Acta, vol. 150, no. 1, pp. 15-19, 2005.

[26] Q. Jia, X. Kong, W. Zhou, and L. Bi, "Flow injection online preconcentration with an ion-exchange resin coupled with microwave plasma torch-atomic emission spectrometry for the determination of trace rare earth elements," Microchemical Journal, vol. 89, no. 1, pp. 82-87, 2008.

[27] J.-S. Kim, C. Han, and J.-H. Wee, "Effect of polyvinyl alcohol on rare earths ( $\mathrm{Gd}$ and $\mathrm{Tb}$ ) separation by extraction resin," Talanta, vol. 68, no. 3, pp. 963-968, 2006.

[28] V. K. Jain, A. Handa, S. S. Sait, P. Shrivastav, and Y. K. Agrawal, "Pre-concentration, separation and trace determination of lanthanum(III), cerium(III), thorium(IV) and uranium(VI) on polymer supported O-vanillinsemicarbazone," Analytica Chimica Acta, vol. 429, no. 2, pp. 237-246, 2001.

[29] L. Jelinek, Y. Wei, T. Arai, and M. Kumagai, "Selective Eu(III) electro-reduction and subsequent separation of $\mathrm{Eu}(\mathrm{II})$ from rare earths(III) via HDEHP impregnated resin," Solvent Extraction and Ion Exchange, vol. 25, no. 4, pp. 503-513, 2007.

[30] S. R. Dave, H. Kaur, and S. K. Menon, "Selective solid-phase extraction of rare earth elements by the chemically modified Amberlite XAD-4 resin with azacrown ether," Reactive and Functional Polymers, vol. 70, no. 9, pp. 692-698, 2010.

[31] V. Diniz and B. Volesky, "Biosorption of La, Eu and Yb using Sargassum biomass," Water Research, vol. 39, no. 1, pp. 239-247, 2005.
[32] K. Jankowski, J. Yao, K. Kasiura, A. Jackowska, and A. Sieradzka, "Multielement determination of heavy metals in water samples by continuous powder introduction microwave-induced plasma atomic emission spectrometry after preconcentration on activated carbon," Spectrochimica Acta Part B: Atomic Spectroscopy, vol. 60, no. 3, pp. 369-375, 2005.

[33] H. M. Marwani, H. M. Albishri, E. M. Soliman, and T. A. Jalal, "Selective adsorption and determination of hexavalent chromium in water samples by chemically modified activated carbon with tris(hydroxymethyl)aminomethane," Journal of Dispersion Science and Technology, vol. 33, no. 4, pp. 549-555, 2012.

[34] P. Biparva and M. R. Hadjmohammadi, "Selective separation/preconcentration of silver ion in water by multiwalled carbon nanotubes microcolumn as a sorbent," Clean: Soil, Air, Water, vol. 39, no. 12, pp. 1081-1086, 2011.

[35] H. M. Marwani, H. M. Albishri, T. A. Jalal, and E. M. Soliman, "Activated carbon immobilized dithizone phase for selective adsorption and determination of gold(III)," Desalination and Water Treatment, vol. 45, no. 1-3, pp. 128-135, 2012.

[36] Y.-S. Ho and A. E. Ofomaja, "Biosorption thermodynamics of cadmium on coconut copra meal as biosorbent," Biochemical Engineering Journal, vol. 30, no. 2, pp. 117-123, 2006.

[37] Z. Salem and K. Allia, "Cadmium biosorption on vegetal biomass," International Journal of Chemical Reactor Engineering, vol. 6, article A10, 2008.

[38] X.-J. Wang, S.-Q. Xia, L. Cwen, J.-F. Zhao, J.-M. Chovelon, and J.-R. Nicole, "Biosorption of cadmium(II) and lead(II) ions from aqueous solutions onto dried activated sludge," Journal of Environmental Sciences, vol. 18, no. 5, pp. 840-844, 2006.

[39] C. Green-Ruiz, V. Rodriguez-Tirado, and B. Gomez-Gil, "Cadmium and zinc removal from aqueous solutions by Bacillus jeotgali: $\mathrm{pH}$, salinity and temperature effects," Bioresource Technology, vol. 99, no. 9, pp. 3864-3870, 2008.

[40] S. B. Khan, M. M. Rahman, H. M. Marwani, A. M. Asiri, and K. A. Alamry, "An assessment of zinc oxide nanosheets as a selective adsorbent for cadmium," Nanoscale Research Letters, vol. 8, no. 1, pp. 1-8, 2013.

[41] S. Schiewer and S. B. Patil, "Pectin-rich fruit wastes as biosorbents for heavy metal removal: equilibrium and kinetics," Bioresource Technology, vol. 99, no. 6, pp. 1896-1903, 2008.

[42] G. Mckay, "The Adsorption of basic dye onto silica from aqueous solution-solid diffusion model," Chemical Engineering Science, vol. 39, no. 1, pp. 129-138, 1984.

[43] Y. S. Ho, D. A. J. Wase, and C. F. Forster, "Kinetic studies of competitive heavy metal adsorption by sphagnum moss peat," Environmental Technology, vol. 17, no. 1, pp. 71-77, 1996.

[44] I. Langmuir, "The constitution and fundamental properties of solids and liquids," The Journal of the American Chemical Society, vol. 38, no. 2, pp. 2221-2295, 1916.

[45] G. McKay, H. S. Blair, and J. R. Gardner, "Adsorption of dyes on chitin. I. Equilibrium studies," Journal of Applied Polymer Science, vol. 27, no. 8, pp. 3043-3057, 1982.

[46] M. M. Rao, D. H. K. K. Reddy, P. Venkateswarlu, and K. Seshaiah, "Removal of mercury from aqueous solutions using activated carbon prepared from agricultural by-product/waste," Journal of Environmental Management, vol. 90, no. 1, pp. 634643, 2009.

[47] Y. S. Ho and G. McKay, "The kinetics of sorption of divalent metal ions onto sphagnum moss peat," Water Research, vol. 34, no. 3, pp. 735-742, 2000. 

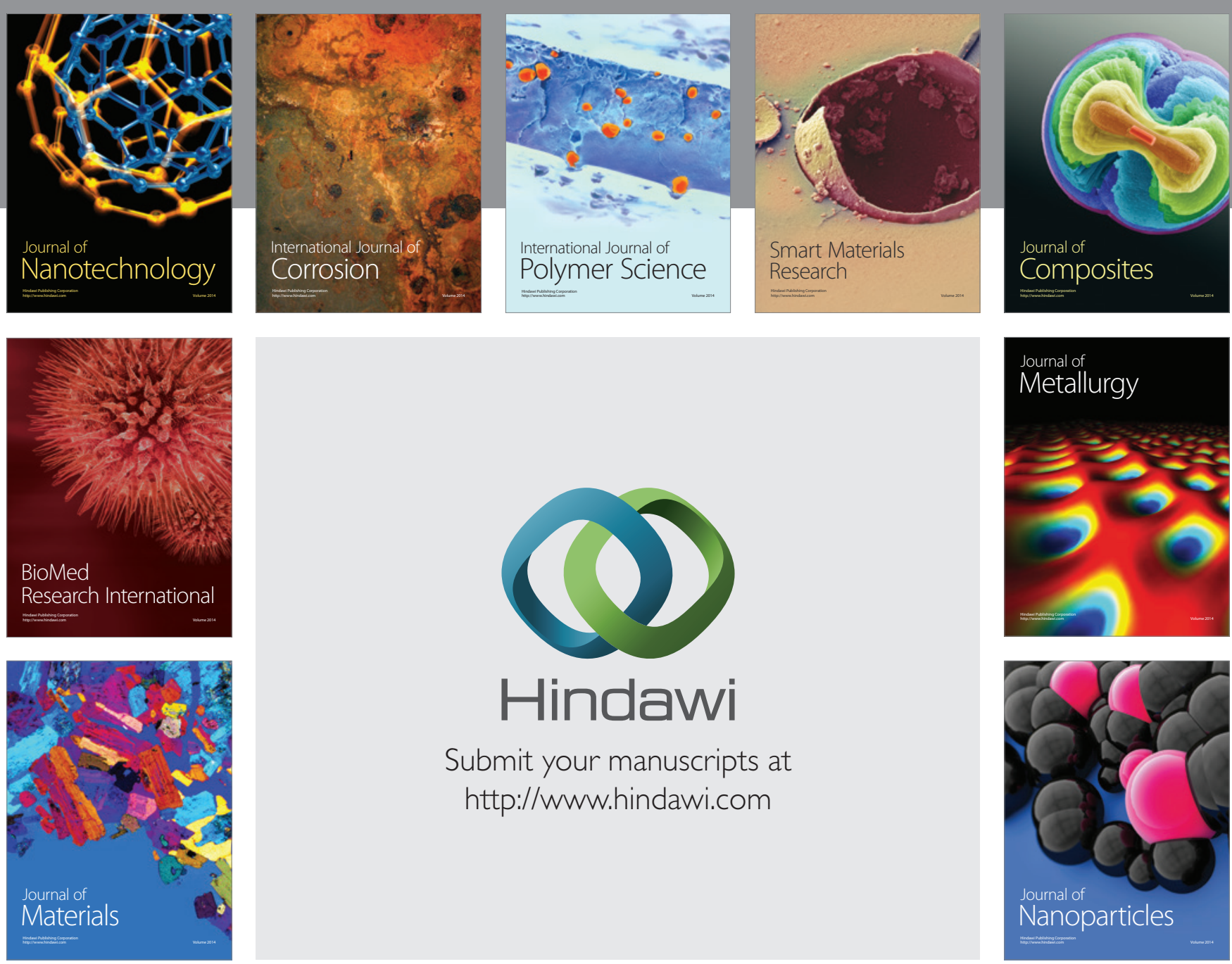

Submit your manuscripts at http://www.hindawi.com
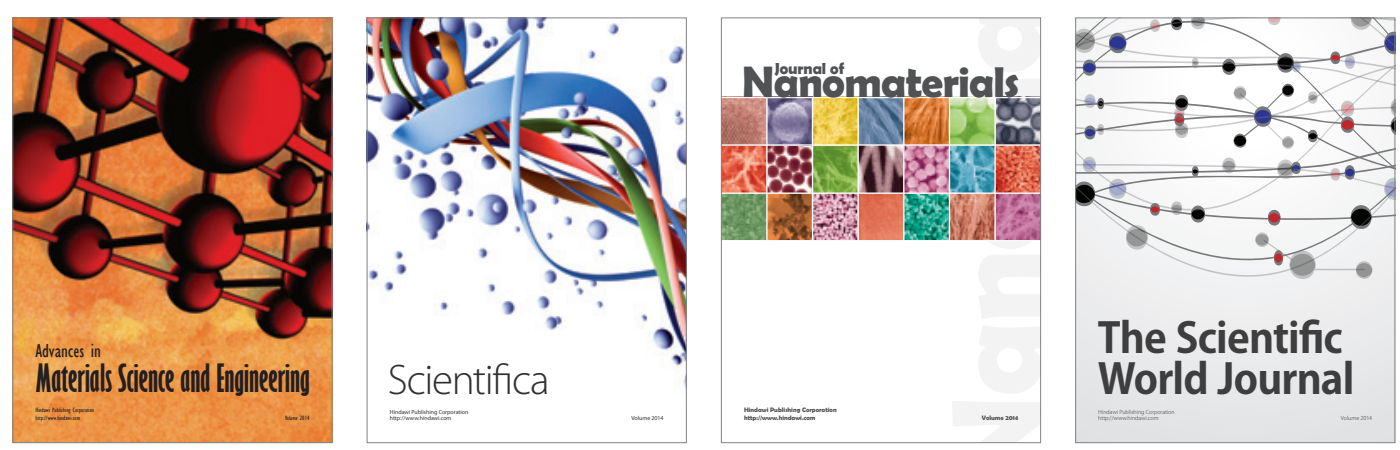

\section{The Scientific World Journal}
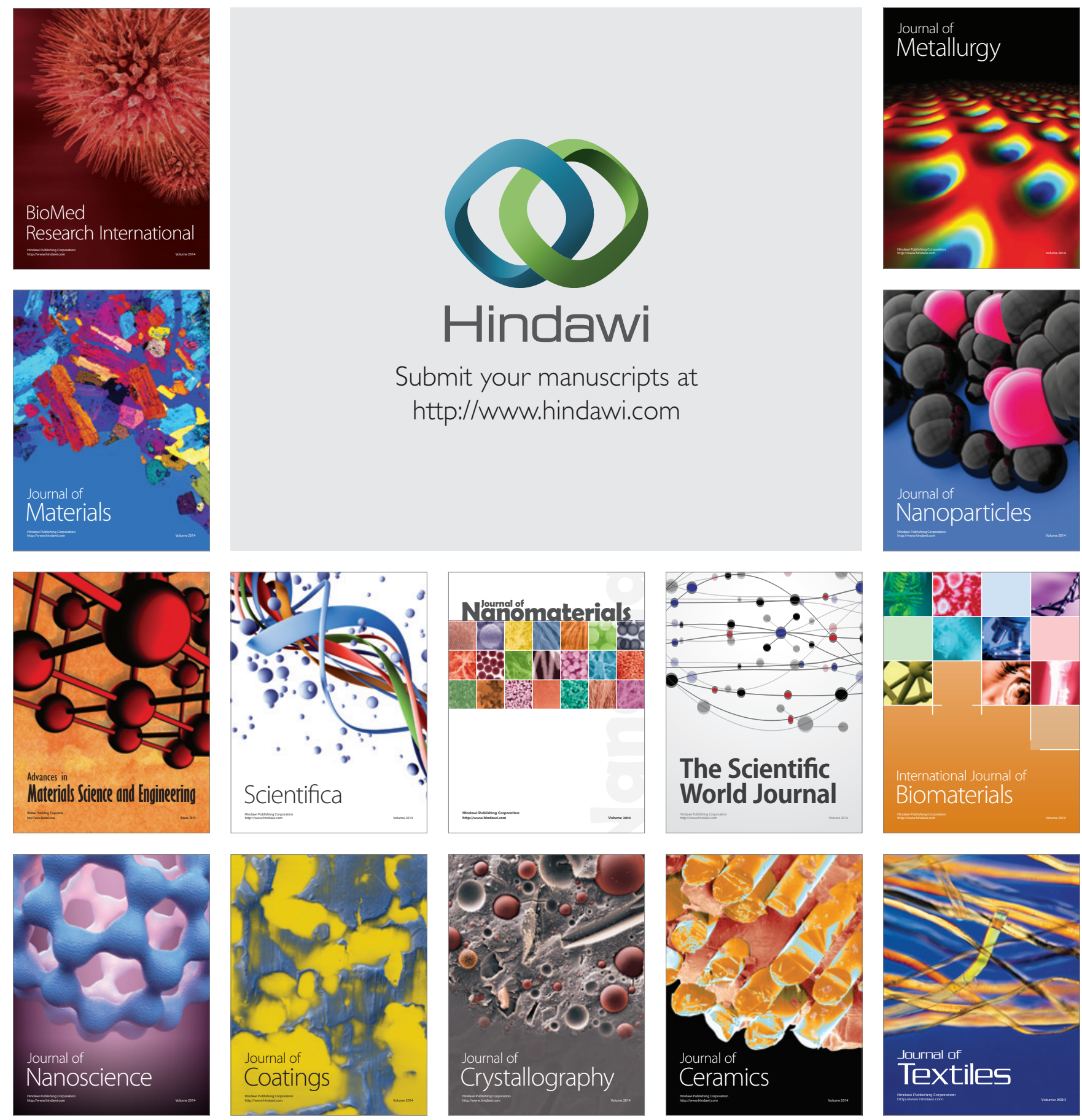